\title{
Optimized Level Set Method for Segmentation of SAR Images using Adaptive Fuzzy-K-Means Clustering
}

\author{
Chenigaram Kalyani, Lalitha Nagapuri,Chinta nirosha, Azmeera Srinivas
}

\begin{abstract}
The complications that occurred in remote sensing image information and analysis algorithms growth of a large scale image segmentation haven't kept a place with the requirement for the methods which to develop the final accuracy of object detection as well as the recognition. Traditional Level set segmentation methods which are Chan-Vese (CV), Image and Vision Computing (IVC) 2010, ACM with SBGFRLS, and Online Region-Based ACM (ORACM) are suffered from more amounts of time complexity, as well as low segmentation accuracy due to large intensity homogeneities and the noise at which the region based segmentation is impossible. So this is the reason, we proposed a navel hybrid methodology called adaptive particle swarm optimization (PSO) based Fuzzy K-Means clustering algorithm. The proposed approach is diversified into two stages; in stage one, pre-processing the input image to improve the clustering efficiency and overcome the obstacles present in traditional methods by using particle swarm optimization (PSO) and Adaptive Fuzzy K-means clustering algorithm. With the help of the PSO algorithm, we get the "optimum" pixels values are extracted from the input SAR images, these optimum values are automatically acted as clusters centers for Adaptive Fuzzy K-Means Clustering instead of random initialization from the original image. The pre-processing segmentation result improved the clustering efficiency but suffers from few drawbacks such as boundary leakages and outliers even particle Swarm optimization is used. To overcome the above drawbacks post-processing is needed to facilitate the superior segmentation results with the help of the level set method. It utilizes an efficient curve deformation driven by external and internal forces to capture the important structures (usual edges) in an image. The combined approach of both pre-processing and post-processing which is called Particle Swarm Optimization based Adaptive Fuzzy-K-Means (AFKM) clustering via the level set method. The proposed approach is successfully implemented on large
\end{abstract}

Revised Manuscript Received on February 05, 2020.

* Correspondence Author

Chenigaram Kalyani*, Department of ECE, Kamala Institute of Technology and Science, Singapur, Huzurabad, Telangana, India. Email: kalyanichinegaram@gmail.com

Nagapuri Lalitha, Department of ECE, Kamala Institute iof Technology and Science, Singapur, Huzurabad, Telangana, India. Email: penchalalalitha@gmail.com

Chinta Nirosha, Department of ECE , DRK College of Engineering

And Technology, Hyderabad, Telangana, India. Email: inirosha.borra@gmail.com

Azmeera Srinivas, Assistant Professor, iDepartment iof iECE, KITS Warangal, Telangana, India. Email:srinivasazmeera85@gmail.com

(C) The Authors. Published by Blue Eyes Intelligence Engineering and Sciences Publication (BEIESP). This is an open access article under the CC BY-NC-ND license (http://creativecommons.org/licenses/by-nc-nd/4.0/) scale remote sensing imagery and the dataset are taken from the open-source NASA earth observatory database for segmenting the oil slicker creeps, oil slicker regions, typhoon, soulnik and the Gulf of Alaska, etc. So here in this, the proposed new method had feasibility and efficiency which could attain the high accurate segmentation results when compared with the traditional level set methods.

Keywords: Remote Sensing Images, Image Segmentation, Adaptive Fuzzy-k-Means clustering, and Fast Level Set Method.

\section{INTRODUCTION}

Study and analysis of earth observation images like oil spills, cyclones, fire and still more.is one of the major tasks were it consists of segmentation of an image, enhancement, and representation, etc. So here, the work is done on the segmentation of oil slicker creeps image, typhoon soulik image, oil slick Image and Gulf of Alaska image which were taken from the NASA earth observatory database. Attaining the data about an object without considering the physical information of an object and thus in contrast to onsite observation which had been done only by remote sensing. In numerous fields, remote sensing is utilized, along with the geography, land surveying as well as Earth Science disciplines.

Depending on the propagated signals like Electro-magnetic radiation at present remote sensing- term denotes the utilization of technologies like satellite depending on the sensor to classify and sense the objects like surfaces, atmosphere, and oceans on earth. The classifications of remote sensing are of two types. The foremost one is the "active remote sensing", where the signal is emitted through the satellite or an aircraft were the object reflections are detected by a sensor. The next type of remote sensing classification is "passive remote sensing" at which the sensor is used to detect the sunlight reflection [1-2].

Recently in image segmentation, the applications of remote sensing along with object detection as well as image classification were involved in research progress. In computer vision and image processing "Image Segmentation" plays a vital role. During the segmentation of remote sensing images, a group of pixels that represents similar will be in the same region at the same time the dissimilar pixels are in different regions.

Among numerous segmentation strategies, for the most part, we go over clustering analysis. A few changed clustering algorithms had acquainted and demonstrated to be active for image segmentation. 
In remote sensing images, clustering precision can be explicitly updated or created by the procedure known as a "particle swarm advancement PSO" were the noise present in images could likewise be diminished. In 1995, PSO [10] was presented by the Russell Eberhart furthermore with James Kennedy. Originally, these two were started emerging computer simulation software of birds flocking running around the nourishment sources, at that point prior appreciated how their algorithm will get dealt with optimized issues. The technique can be applied to optimized issues of huge measurements, regularly delivering prominent arrangements more quickly than elective methodologies and it has a low convergence rate in an iterative procedure.

Mostly the significant difficulties in image analysis are image segmentation. For different applications, numerous segmentation algorithms have been presented and created. Now and again inadmissible outcomes have been experienced, for several existing segmentation algorithms such as thresholding region growing and clustering techniques. Here we propose a new kind of clustering method for efficient segmentation of regions present in large scale remote sensing images. So the proposed method i.e., Adaptive Fuzzy K-Means clustering which improves the clustering efficiency at the same time boundary leakages which are present during the clustering process. To overcome the difficulties raised during the clustering process we do introduce a new level set formulation for accurate as well as robust segmentation and also the boundary leakages are reduced by LSF [5-6].This paper had systematized as follows: Materials and methods are discussed in chapter 2.A modified version of the level set method are proposed in chapter3. A detailed explanation of the experimental results is discussed in chapter 4. Finally, conclusions are presented in chapter 5 .

\section{MATERIALS AND METHODS}

Based on the literature review on existing level set methods such as IVC 2010, Chan-Vese (C-V) model, ACM with SBGFRLS, ORACM. These methods suffered from few limitations such as slow and complex, weak edge leaking and poor segmentation results with illumination changes. Improper image acquisitions like inadequate illumination conditions can also lead to poor image segmentation. Though Geodesic ACM was successful in getting improved image segmentation for the images which are having sharp edges, they have the following drawbacks such as unstable evolution, requires periodic re-initialization, Balloon or pressure force causes boundary leakage, slow evolution due to smaller time step.

The performance of active contour models can be improved further by introducing selective additional pre-processing techniques such as one possible way is the combined approach introduced that is fuzzy C-means and K-Means clustering algorithms treated as Adaptive Fuzzy-K-Means (FKM) clustering and a new energy function defined for evolving level sets in the post-processing. With this, accurate image segmentation is possible even for the images captured under any illumination conditions. The proposed work focuses on developing improved image segmentation method based on level sets by Pre-processing the images for better results with existing techniques. Employing a Clustering, the method image segmentation is to segregate an image into various regions with an end goal that each area is homogeneous by using the clustering techniques. So, here in this, we use a clustering technique which is given below [4]:

\section{- Adaptive Fuzzy K-means Clustering Algorithm} (AFKM) section 2.2.

\subsection{Determining Optimum Pixels with PSO algorithm:}

In the year 1995 Kennedy along with Eberhart [7] remained charged to have an improvement in PSO by the scavenging behavior of gatherings of fowls alongside schools of a fish. Each particle has its area just as velocity, at which a quality addresses the elements of a decision in the present accentuation alongside the improvement vector for the accompanying cycle, independently. A velocity moreover the situation of each particle as necessities be assortments to the data which is participated in every particle in the present cycle. Every particle can record the individual and resuscitate through cycles or by following a system. The overall best-shared characteristic was described by taking a gander at the individual best acknowledgment of everything being equal. The interest system of PSO incorporates seeing the new velocity remembering the ultimate objective to have figuring of a position which is another at the accompanying technique according to the velocity which is remarkable of each particle $-\left(\mathrm{V}_{\mathrm{i}}\right)$, the individual best commonality of each particle $-\left(x_{p}(\mathrm{i})\right)$, and the worldwide best nature of each particles- $\left(x_{g}\right)$. The basic Step is to instate the particle swarm and besides consolidate particle velocity and position in the space looking. A while later, find out the wellbeing of the particle swarm to revive the individual best acknowledgment of each particle and also the overall best nature of each particle. The most crucial planning step is to calculate the novel velocity just as the area of each particle in the accompanying technique by using the conditions (1) and (2).

$$
\begin{aligned}
& v_{i d}\left(\mathrm{t}_{1}+1\right)=\mathrm{W}^{*} \mathrm{v}_{i d}\left(\mathrm{t}_{1}\right)+\mathrm{c}_{1} r_{1}\left(\mathrm{x}_{p(\mathrm{id})}\left(\mathrm{t}_{1}\right)-\mathrm{x}_{i d}\left(\mathrm{t}_{1}\right)+\right. \\
& \left.\mathrm{C}_{2} \mathrm{r}_{2}\left(\mathrm{x}_{g d}\left(\mathrm{t}_{1}\right)-\mathrm{x}_{i d}\left(\mathrm{t}_{1}\right)\right)\right)
\end{aligned}
$$

$v_{i d}\left(\mathrm{t}_{1}\right)$ Represents velocity value of $d_{t h}$ Dimension' of $i_{t h}$ particle in an $t_{t h}$ iteration.

Variable $X_{i d}\left(\mathrm{t}_{1}\right)$ represents location of $d_{t h}$-dimension if $i_{t h}$ particle in $t_{t h}$ - iteration.

Variable $W$ shows weight of inertia

$c_{1}$ is for self-cognition acceleration co-efficient; $c_{2}-$ social-cognition acceleration co-efficient.

$$
x_{i d}\left(\mathrm{t}_{1}+1\right)=\mathrm{x}_{i d}\left(\mathrm{t}_{1}\right)+\mathrm{v}_{\text {id }}\left(\mathrm{t}_{1}+1\right)
$$

Equation (2) shows a new location of each particle is refreshed using a first position alongside the new velocity by a condition (1).At which $r_{1}$ and additionally $r_{2}$ were produced independently. The scope of uniform appropriated arbitrary numbers are $(0,1)$. The flowchart of the PSO algorithm [35] clarified in the below figure. 


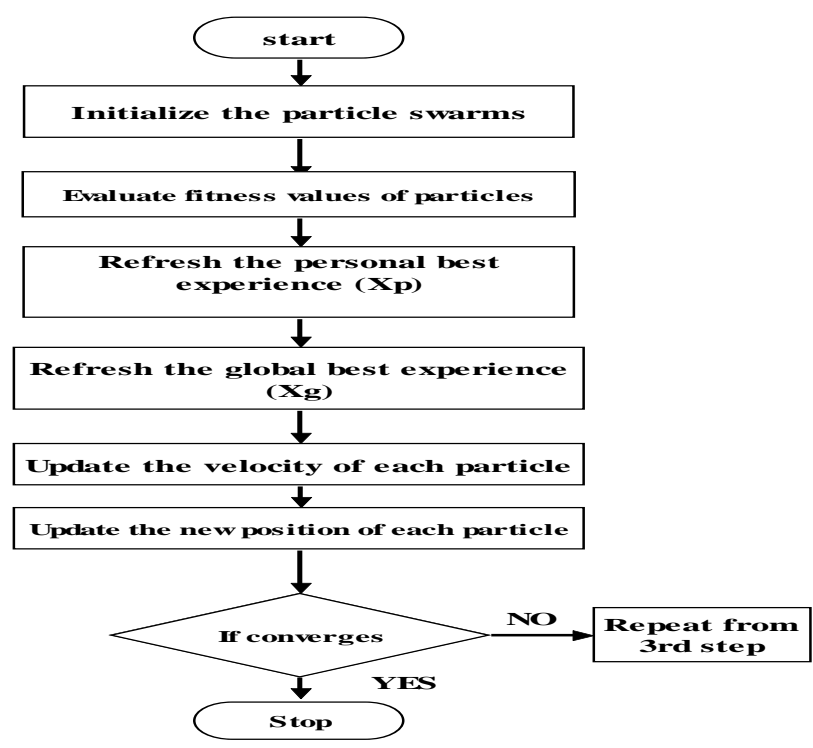

Fig.1. Flowchart representation for PSO algorithm

\subsection{Adaptive Fuzzy K-means Clustering Algorithm (AFKM):}

In this method, image segmentation applies to general images. It is best suited for medical, remote sensing as well as microscopic images that are captured by the electronic products. This algorithm gives better quality and the adaptive clustering procedure when compared with the other conventional methods or clustering methods [40].

\subsection{1 iAlgorithm iSteps ifor iFuzzy iK-means iClustering iAlgorithm}

FKM clustering algorithm incorporates both the K-Means and Fuzzy C-Means clustering algorithm. The implementation of the proposed method is explained by considering an image that is a digital one with $\mathrm{R} * \mathrm{~S}$ pixels (the number of rows is denoted by $\mathrm{R}$ and number of columns is denoted by $\mathrm{S}$ ) which had to be clustered into NC clusters. Consider an assumed pixel $\mathrm{p}(\mathrm{x}, \mathrm{y})$ and $\mathrm{cj}$ as a jth center. For K-means depending upon the Euclidean distance, a group of the data was assigned to the closest center. Each position center is calculated by an equation given below

$$
c_{j}=\frac{1}{n_{c_{j}}} \sum_{x \in c_{j}} \sum_{y \in c_{j}} p(\mathrm{x}, \mathrm{y})
$$

$$
\mathrm{j}=1,2,3 \ldots, \mathrm{nc}
$$

Where, $\mathrm{x}=1,2,3, \ldots \ldots \ldots \ldots \ldots, \mathrm{s} ;=1,2,3, \ldots \ldots \ldots \ldots, \mathrm{R}$;

Similarly in FCM, allocating the data member consecutively to greater than one class this process is depended on a membership function given below.

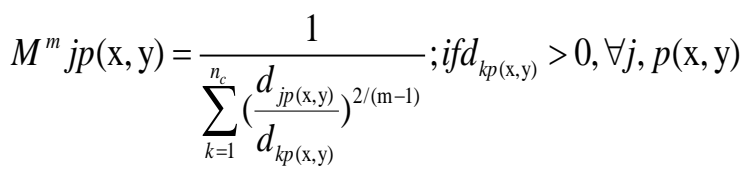

$$
\left\{\begin{array}{l}
M^{m} k p(\mathrm{x}, \mathrm{y})=1 \\
M^{m} j p(\mathrm{x}, \mathrm{y})=0 ; \operatorname{forp}(\mathrm{x}, \mathrm{y}) \neq \mathrm{k} \\
i f d_{k p(x, y)}=0 ;
\end{array}\right.
$$

From the above equation the distance from the point (x, y) to the present $\mathrm{j}$ cluster center is $d_{j p(x, y)}$. The distance from the point $(\mathrm{x}, \mathrm{y})$ to the other $\mathrm{k}$ cluster centers is $d_{k p(x, y)}$.Several centers are represented by ${ }_{c}$.Integer is $\mathrm{m}: \mathrm{m}>1$ determines degree of a fuzziness.

In proposed method AFKM algorithm, at certain esteem all centers were initialized. So to ensure a better clustering method equation (3) will be no more to update the center. Hence due to this, we utilize the fuzziness and its belonging concepts in the proposed method. So here in this, a membership function $M^{m} j p(\mathrm{x}, \mathrm{y})$ is determined with the help of equation (4\&5).To attain a good process of clustering some changes were did in AFKM algorithm. The degree of belongingness $B_{j}$ is calculated for every cluster after specifying the membership to all the individual data. When the degree of belongingness is higher, then it shows a strong relationship between the center and its' members at which it ensures an improved clustering data. The degree of belongingness equation is as below:

$$
B_{j}=\frac{C_{j}}{M_{j p(\mathrm{x}, \mathrm{y})}^{m}}
$$

To progress the clustering method, we need to update the degree of the membership function. The esteem of $M^{m}{ }_{j p(\mathrm{x}, \mathrm{y})}$ is modified in an iteration accordingly as

$\left(\mathrm{M}_{j p(\mathrm{x}, \mathrm{y})}^{m}\right)^{\prime}=M_{j p(\mathrm{x}, \mathrm{y})}^{m}+\Delta M_{j p(\mathrm{x}, \mathrm{y})}^{m}$

At which, $\left(\mathrm{M}^{m}{ }_{j p(\mathrm{x}, \mathrm{y})}\right)^{\prime} \quad$ Represents a new membership. $\Delta M^{m}{ }_{j p(\mathrm{x}, \mathrm{y})}$ is defined as:

$$
\Delta M_{j p(\mathrm{x}, \mathrm{y})}^{m}=\alpha\left(\mathrm{c}_{j}\right)\left(\mathrm{e}_{j}\right)
$$

$\alpha$-is a constant designed with a value between 0 and $1 . \mathrm{e}_{j}$ Value is calculated by using an equation

$$
e_{j}=B_{j}-\hat{B}_{j}
$$

$\hat{B}_{j}$ Degree of belongingness representation.

Lastly, the novel center positions of total current clusters are calculated depending on optimized or novel membership function as

$$
c_{j}=\frac{\sum_{x \in c_{j}} \sum_{y \in c_{j}}\left(\mathrm{M}_{j p(\mathrm{x}, \mathrm{y})}^{m}\right)^{\prime} p(\mathrm{x}, \mathrm{y})}{\sum_{x \in c_{j}} \sum_{y \in c_{j}}\left(\mathrm{M}_{j p(\mathrm{x}, \mathrm{y})}^{m}\right)^{\prime}}
$$


The process is repeated until the values of all the centers are no longer discrepancy.

\section{PROPOSED METHOD}

The proposed method diversified into two stages, which is called pre-processing and post-processing an input image. So here, in the pre-processing by using a new hybrid approach of conventional clustering is proposed, which is called Adaptive Fuzzy-K-Means (AFKM) clustering for improves the clustering efficiency. The detailed description of pre-processing is discussed in section 3. In the later stage, which is called Post-processing by using the adaptive level Set method, it is necessary to remove the outliers, boundary leakages, and to get the smoothed segmentation image. A brief explanation and mathematical implementation to level set in the below section 4.1

\subsection{Implementation to Fast Level Set Approach}

In post-processing we use the level set method, to overcome the obstacles which are present in the pre-processing. It is necessary to initialize the contour on AFKM clustered image instead of the original input image. In traditional level set methods, with the help of two components which are called data term as well as regularization term, curve evolution is controlled [17]. Data term attracts a curve towards the boundary at the same time the second one is to regulate the regularity of a curve. Now, let us discuss first the algorithm which had been proposed with a proposed data term later the implementation of the proposed algorithm had been elaborated.

The Chan-Vese $(\mathrm{C}-\mathrm{V})$ Energy functional $F\left(\mathrm{C}_{1}{ }^{\prime}, \mathrm{C}_{2}{ }^{\prime}, \mathrm{c}\right)$ is defined as below:

$$
\begin{aligned}
& F\left(\mathrm{c}_{1}{ }^{\prime}, \mathrm{c}_{2}{ }^{\prime}, \mathrm{c}\right)=\mu \text {. Length }(\mathrm{c})+\lambda_{1} \int_{\text {inside (c) }}\left|I_{f k m}-c_{1}^{\prime}\right|^{2} \\
& +\lambda_{2} \int_{\text {outside(c) }}\left|I_{f k m}-c_{2}{ }^{\prime}\right|^{2} d x d y
\end{aligned}
$$

Length(c): length of the curve $\mathrm{C}$, it treats as a regularizing term in order to have a smooth evolving level curve. The parameters $\mu \geq 0, \lambda 1, \lambda 2>0$ represent the weighting co-efficient to control the level set curve. The mean intensities $\mathrm{c}^{\prime}$ ' and c2 of an image-Ifkm, which evolve the curve inside as well as the outside in an image. The LSM energy function defined in eq.(11) is shown below:

$$
\frac{\partial \phi}{\partial t}=\delta_{\varepsilon}(\phi)\left[\mu \cdot \operatorname{div}(\nabla \phi /|\nabla \phi|)-\lambda_{1}\left(\mathrm{I}_{A f k m}-\mathrm{c}_{1}{ }^{\prime}\right)^{2}+\lambda_{2}\left(\mathrm{I}_{A f k m}-\mathrm{c}_{2}{ }^{\prime}\right)^{2}\right]
$$

From the above equation (12) we say that, Level set function $\varphi$, is designed based on 'signed distance function' (SDF), Dirac delta function $\delta \varepsilon(\varphi)$, Artificial time' $t$ ', Level mean curvature is $\operatorname{div}(\nabla \varphi /|\nabla \varphi|), \mu^{*} \operatorname{div}(\nabla \varphi /|\nabla \varphi|) \delta \varepsilon(\varphi)$ - mean curvature-based regularization term which are attained by minimizing a function $\mu$ - Length(c) in an above. Chan-Vese (CV) model had become popular in the processing of remote-sensing images. From equation (12) we have five constraints, $(\varepsilon, \mu, \lambda 1, \lambda 2, \Delta \mathrm{t})$ need to be tuned before it can be used effectively. In [18-22] the methods with fewer constraints are advantageous. Accordingly, we intend to simplify the few constraints in the CV prototype.
Let we consider $\mu=0 ; \lambda 1=\lambda 2=\lambda$ and then the equation (12) could be re-written as below:

$$
\frac{\partial \phi}{\partial t}=\delta_{\varepsilon}(\phi)\left[\lambda\left(\mathrm{c}_{1}{ }^{\prime}-\mathrm{c}_{2}{ }^{\prime}\right)\left(2 \mathrm{I}_{A f k m}-\mathrm{c}_{1}{ }^{\prime}-\mathrm{c}_{2}{ }^{\prime}\right)\right]
$$

In an equation (13) the optimal of a time step for the numerical system had to fulfill the Courant-Friedrichs -Lewy condition i.e., time step needs to be a minute. By allocating $\mu=0$ we could discard the mean curvature-based regularization term, thus allowing the utilization of relatively large time steps to expedite the proposed method. Also, it is reasonable to have $\lambda=\lambda 1=\lambda 2$ why because we had assumed that, boundaries in between the object as well as the background regions are clear [23-28].

In $\left(c_{1}^{\prime}-c_{2}^{\prime}\right)\left(2 I_{A f k m}-c_{1}^{\prime}-c_{2}^{\prime}\right)$ from equation (13) right-hand side represents the real effective part .The data term $\left(2 \mathrm{I}_{A f k m}-\mathrm{C}_{1}^{\prime}-\mathrm{C}_{2}^{\prime}\right)$ was the sign that can be utilized to regulate the direction of a propagating level curve. $\left(c_{1}^{\prime}-c_{2}^{\prime}\right)$ the term could be eliminated due to the insignificant contribution. Besides it is feasible to substitute $\delta \varepsilon(\varphi)$ with $|\nabla \varphi|$. Depending on all these procedures, the following were very much simpler region-based level set formula which could be achieved as:

$$
\frac{\partial \phi}{\partial t}=\lambda\left(2 \mathrm{I}_{A f k m}-\mathrm{c}_{1}^{\prime}-\mathrm{c}_{2}{ }^{\prime}\right)|\nabla \phi|
$$

In an equation (42), a larger esteem of a $\lambda$ could expedite a level curve evolution. To decrease the number of constraints we increase, this prototype by utilizing a larger time step ' $\Delta \mathrm{t}$ ' instead of larger ' $\lambda$ '. Therefore, we remove the ' $\lambda$ ' directly in the equation (14).

The definition of $c_{1}^{\prime}$ and $c_{2}^{\prime}$ is same as in the equation (12). To attain the stable results, we standardize the data term $\left(2 \mathrm{I}_{A f k m}-\mathrm{C}_{1}^{\prime}-\mathrm{C}_{2}^{\prime}\right)$ so, the proposed formula can be written as below [39]:

$$
\frac{\partial \phi}{\partial t}=\frac{2 \mathrm{I}_{A f k m}-\mathrm{C}_{1}{ }^{\prime}-\mathrm{C}_{2}{ }^{\prime}}{\max \left(\left|2 \mathrm{I}_{A f k m}-\mathrm{C}_{1}{ }^{\prime}-\mathrm{C}_{2}{ }^{\prime}\right|\right)}|\nabla \phi|
$$

Here $c_{1}^{\prime}$ and $c_{2}^{\prime}$ are the mean intensities, which is defined as the following

$$
\begin{aligned}
c_{1(\text { inside })}^{\prime} & =\frac{\int_{\text {Domain } \Omega} I_{A f k m}(x, y) \cdot H(\phi) d x d y}{\int_{\Omega} H(\phi) d x d y} \\
c_{2(\text { outside })}^{\prime} & =\frac{\int_{\text {Domain } \Omega} I_{A f k m}(x, y) \cdot(1-H(\phi)) d x d y}{\int_{\Omega}(1-H(\phi)) d x d y}
\end{aligned}
$$

Equations (14) and (15) are the final level set equations, which is utilized only one parameter that is time step ' $\Delta \mathrm{t}$ ', which gives faster curve evolution on adaptive Fuzzy-K-Means clustered images. The proposed fast level set method is well suitable for the accurate and robust segmentation of oil slicker creeps image, typhoon soulik image, oil slick image as well as Flood water images which were shown in the experimental results. 

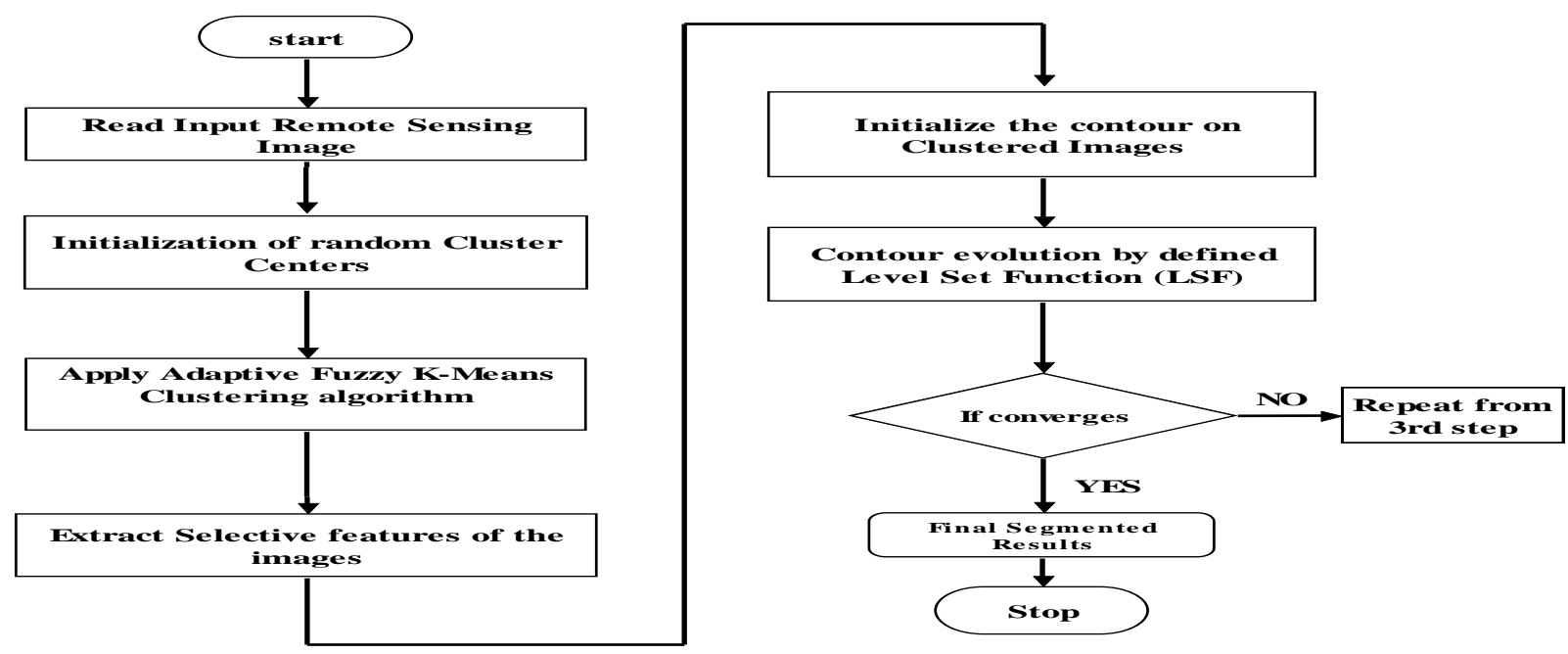

Fig. 2. Flow chart for the proposed Adaptive Fuzzy-K-Means Level Set Method

\section{RESULTS AND CONSIDERATIONS}

The suggested proposed algorithm is implemented on remote sensing images for the segmentation of oil slicker creeps image, typhoon soulik image, the oil slick image and Gulf of Alaska image. The proposed results are analyzed and compared with IVC 2010, Chan-Vese (CV), ACM with SBGFRLS, Online Region-Based ACM (ORACM). The conventional methods IVC 2010 which is proposed by Kaihu Zhang, Chan-Vese, ACM with SBGFRLS, ORACM with the selective local or a global segmentation fails to detect the segmentation accuracy (SA) based on Dice similarity index, Jaccard similarity index, True Negative Fraction, False Negative Fraction, regions and boundaries of a remote)sensing image (oil slicker creeps image, typhoon soulik image, the oil slick image and Gulf of Alaska image) due to improper choosing of controlling parameters and energy function defined in the conventional methods. To overcome the above-mentioned difficulties we were proposing a new improved Fast Level Set method for getting a superior segmented accuracy depending on the Dice similarity index, Jaccard similarity index, True Negative Fraction and False Negative Fraction, along with less computational time. Experimental simulation is performed on four different remote sensing images as shown in figure 3, which depicts the results of pre-processing input images by using Fuzzy-k-means clustering and initialize contour on it.

The proposed algorithm presented here in this paper is compared with the models which were widely used see figure 4, such as Chan-Vese (CV), ACM with SBGFRLS, Online Region-Based ACM (ORACM) methods in terms of an Area covered, Effective Area, less CPU time and Area error from remote sensing images. Similarly, figure 5 shows the final level set contour evolution by the proposed method and its segmenting regions respectively. Our proposed level-set method segmenting the regions accurately and effectively when compared with conventional methods.The database was taken from the https://earthobservatory.nasa.gov/images and NASA database. These images are remodified to 256x256 for the contour evolution of both proposed and traditional methods for preprocessed images. Initial contours for all four images are considered as square-shaped initial contour functions well-defined from 10 to $(\mathrm{N}-100)^{\text {th }}$ pixels of an $\mathrm{NxN}$ size input image. A final contour evolution to the desired output has taken within the range of $50-120$ iterations with less CPU time. Existing level set methods fail to identify the proper edges, regions and boundaries of images for the evolution of the level set contour C. Figure 6, depicts the performance graph of existing and proposed methods in terms of area errors of four different Images respectively. It shows clearly, the proposed method area error would be less compared to all the four existing methods.

The proposed final fast level set segmentation results covered the maximum segmented area when compared with conventional models. The performance parameters of conventional models were tabulated in table 1 and our proposed model was tabulated in table 2 and table 3 respectively. A pixel-based quantifiable evaluation method is used. In this evaluation, the proposed method made a comparison between the final segmented image ' $\mathrm{P}$ ' and the ground truth image ' $Q$ '. The following parameters were used; Dice Similarity Index, Jaccard Similarity Index, True Positive Fraction - (TPF), True Negative Fraction - (TNF), False Positive Fraction - (FPF) and False Negative Fraction - (FNF) [45] defined as:

$$
\begin{aligned}
& \text { Dice }=\frac{2|P \cap Q|}{|P|+|Q|} \text { Jaccard }=\frac{P \cap Q}{P \cup Q} \\
& \mathrm{TPF}=\frac{P \cap Q}{Q} \mathrm{TNF}={ }_{1}-\frac{P-Q}{Q} \\
& \mathrm{FPF}=\frac{P-Q}{Q} ; \quad \text { FNF }=\frac{Q-P}{Q}
\end{aligned}
$$

Note: The parameters like Dice similarity coefficient (DS), Jaccard similarity coefficient (JS), TPF,TNF,FPF,FNF which we considered in our proposed method, the better performance can be achieved by Dice similarity index ,Jaccard similarity index, True Positive Fraction, True Negative Fraction for higher values. Moreover, for higher values of False Positive Fraction, False Negative Fraction it leads to the worst performance. Based on the above-mentioned information, the Dice similarity index, Jaccard similarity index, 
True Negative Fraction and False Negative Fraction of the proposed method gives improved results when compared with the conventional methods.

From the tables 1, 2, and 3 the proposed method is faster, accurate and superior for detection of boundaries, regions, edges in remote sensing images based on Dice similarity coefficient (DS), Jaccard similarity coefficient (JS), True

Simulation results of pre-processing by using adaptive Fuzzy K Means Clustering and Contour Initialization on it:

Column-1

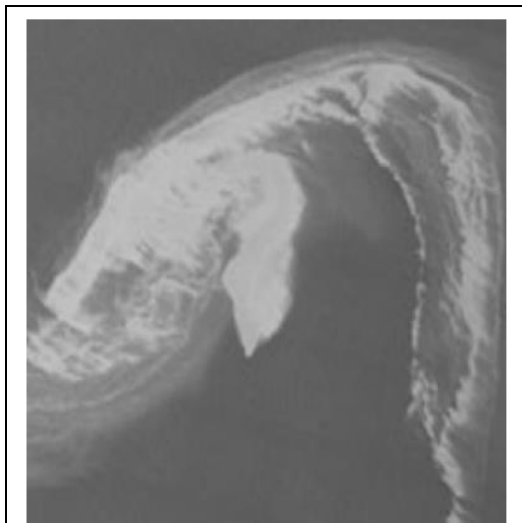

(a)

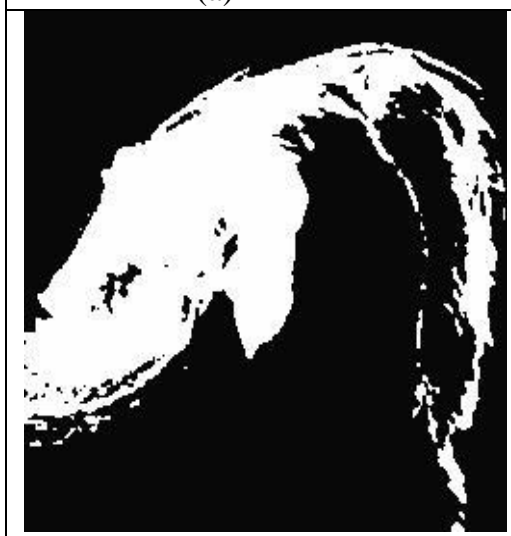

(b)

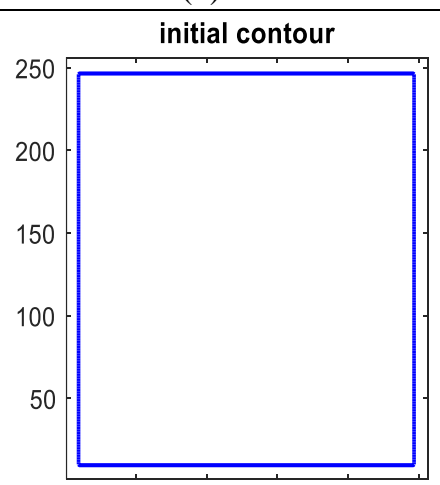

$50 \quad 100 \quad 150 \quad 200 \quad 250$

(c)
Column-2

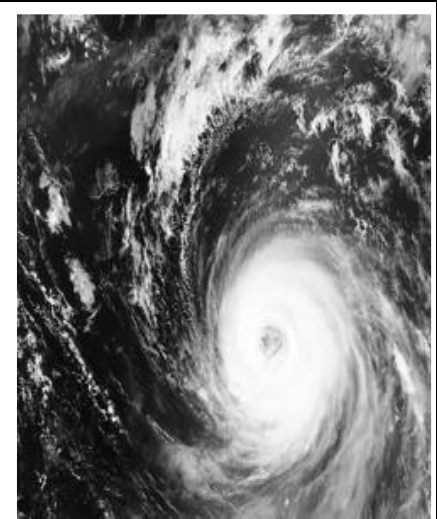

(a)

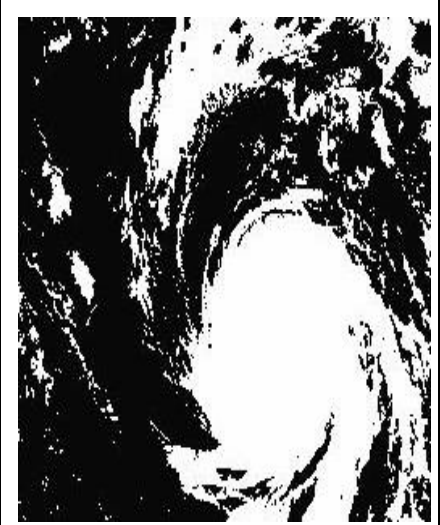

(b)

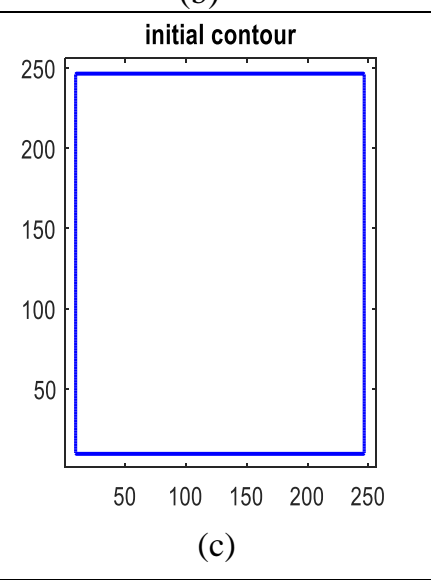

Column-3

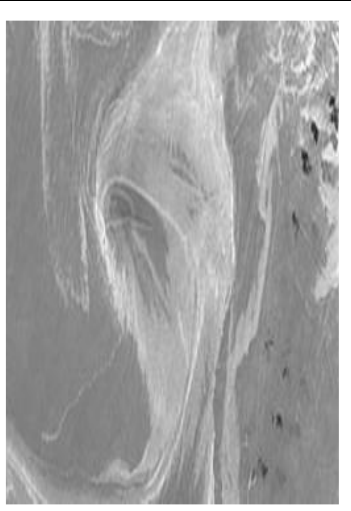

(a)

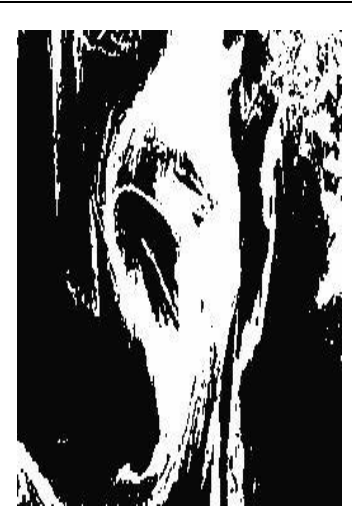

(b)

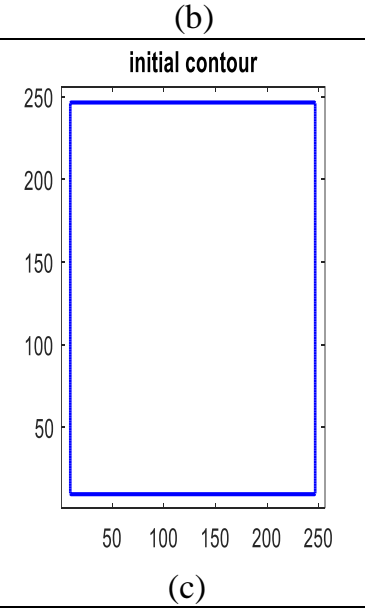

Column-4

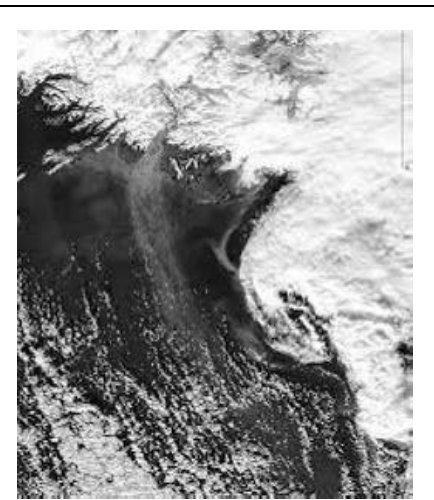

(a)

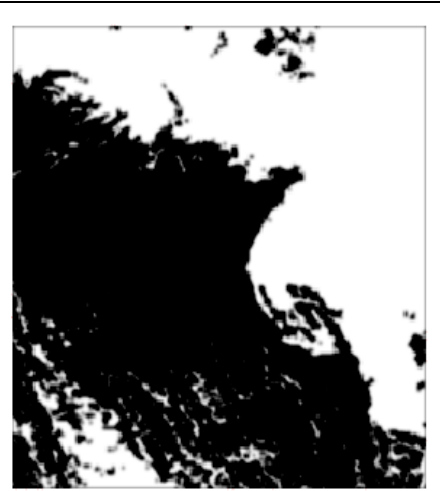

(b)

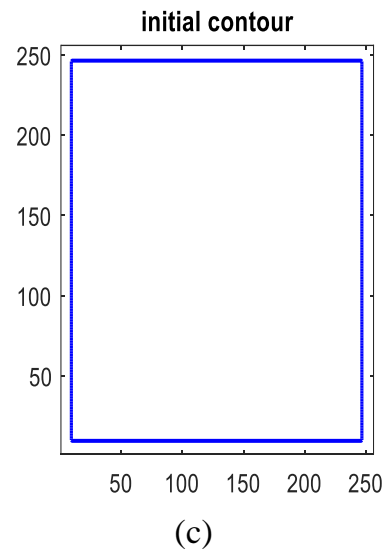

Figure 3 shows the results of pre-processing on SAR images by using Adaptive Fuzzy $\mathrm{K}$ means clustering. First row shows the original SAR images which is taken from the NASA earth observatory data set and Second row shows the corresponding clustered results by using adaptive Fuzzy $\mathrm{K}$ means and finally, the last row depicts the initialization of contour on pre-processed results (means second row images). 
Simulation Results of Existing as well as proposed methods on different SAR images:

Column-1

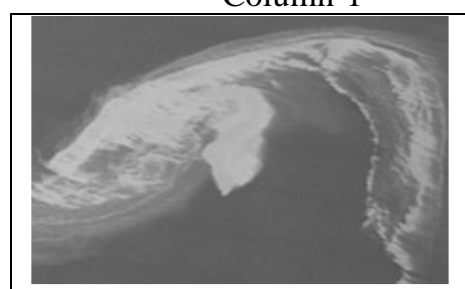

(a)

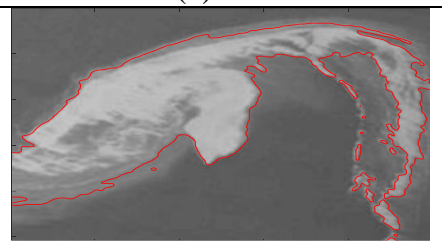

(b)

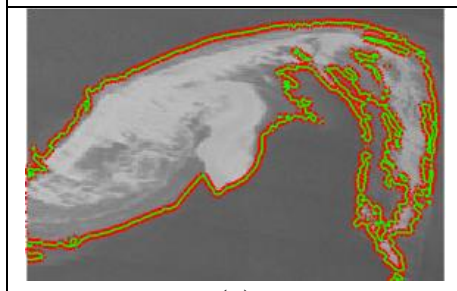

(c)

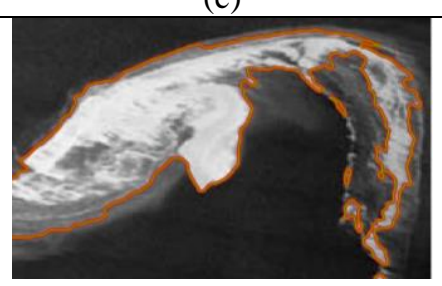

(d)

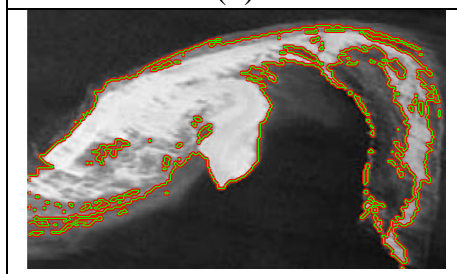

(e)

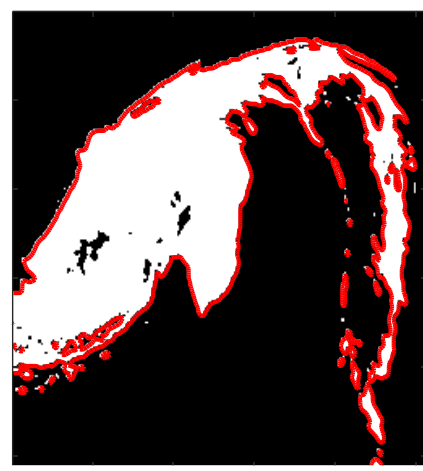

(f)

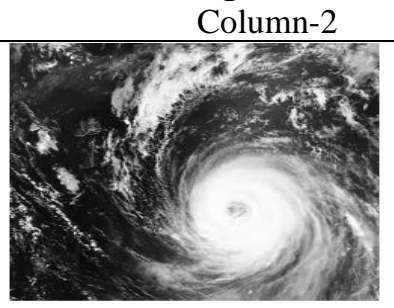

(a)

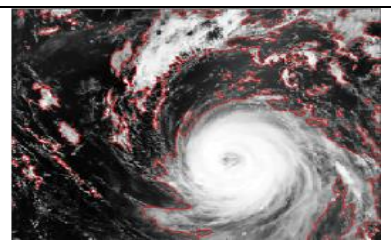

(b)

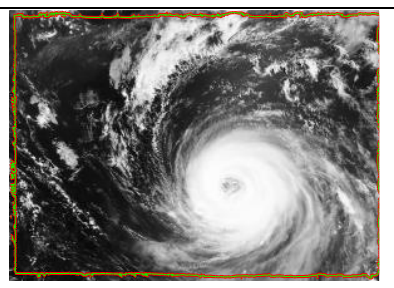

(c)

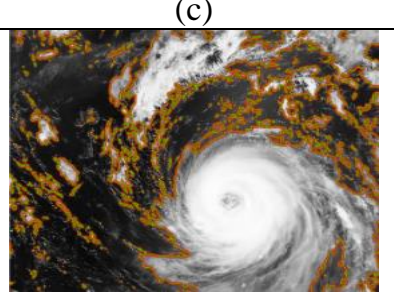

(d)

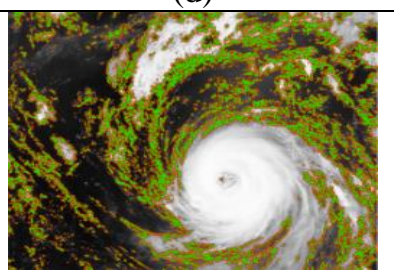

(e)

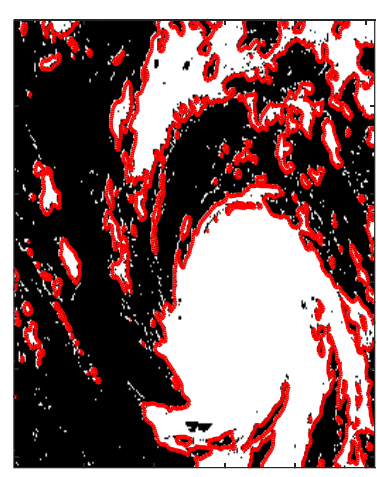

(f)

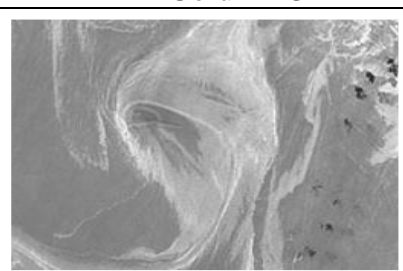

(a)

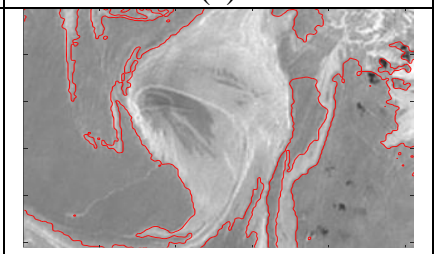

(b)

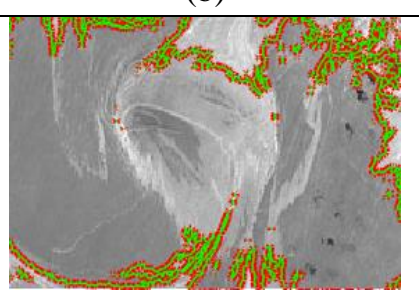

(c)

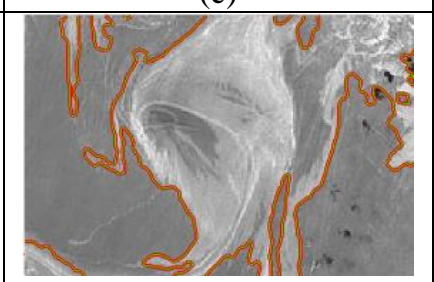

(d)

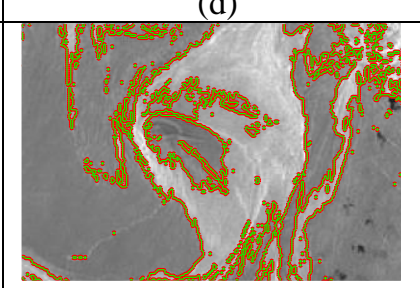

(e)

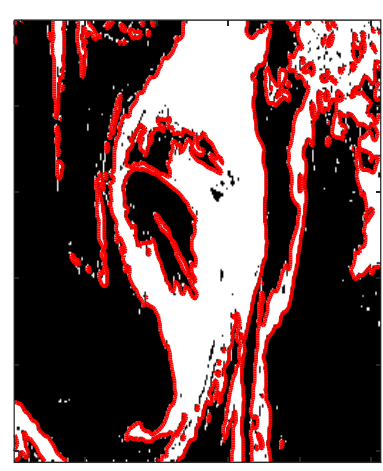

(f)

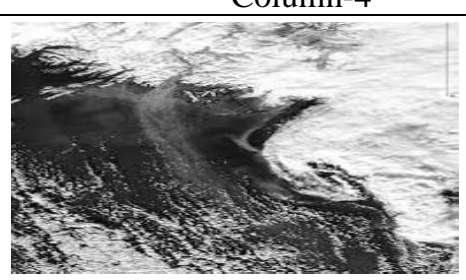

(a)

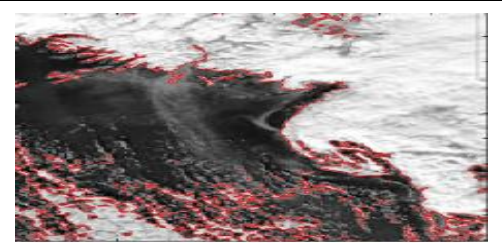

(b)

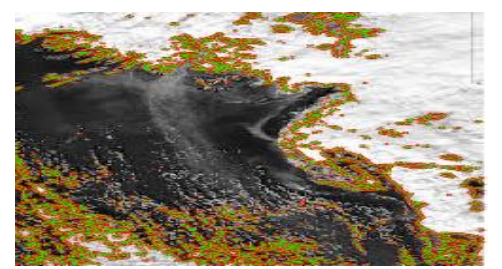

(c)

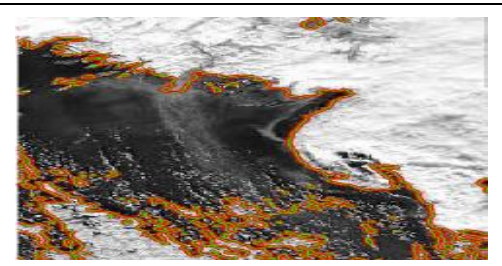

(d)

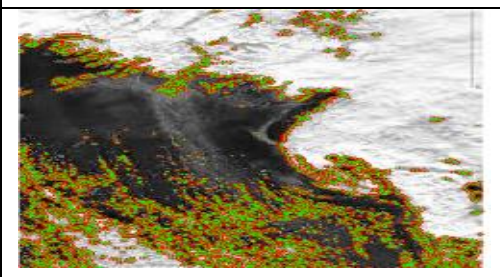

(e)

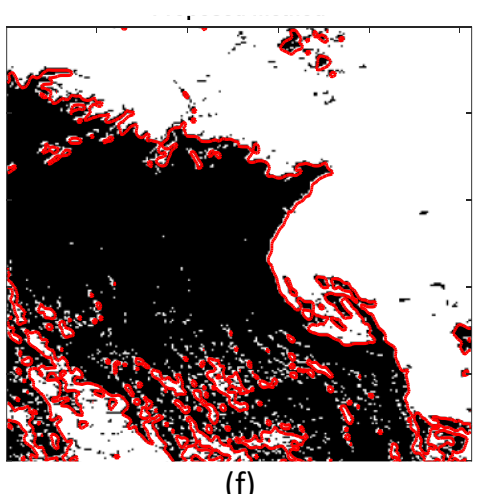

Figure4.Simulation results on different SAR Images, first row shows that original SAR images such as column 1, column 2, column 3 and column 4 are oil slicker creeps, Typhoon soulik, Oil spill and Gulf of Alaska rage images respectively. Similarly Second row, third row and fourth rows depicts the simulation segmentation results of Existing

Level Set methods such as IVC 2010, Chan-Vese (CV),ACM with SBGFRLS, , Online Region Based ACM

(ORACM) model respectively. Finally, the last row shows the final segmentation results of the proposed adaptive Fuzzy K-Means Level Set method.

Retrieval Number: C4858029320/2020@BEIESP DOI: 10.35940/ijeat.C4858.029320 Journal Website: www.ijeat.org
Published By:

2045 Blue Eyes Intelligence Engineering \& Sciences Publication

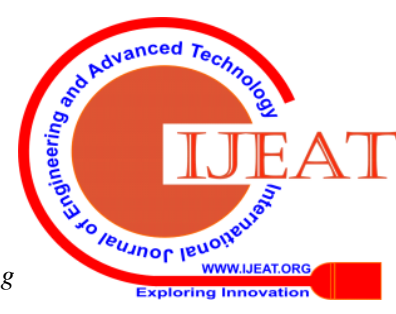


Column-1

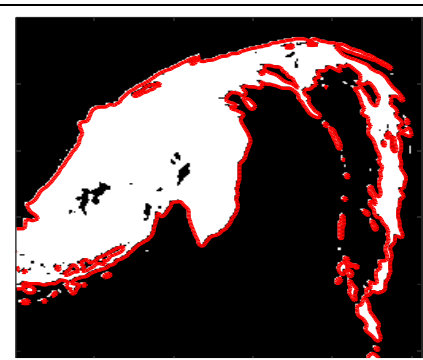

(a)

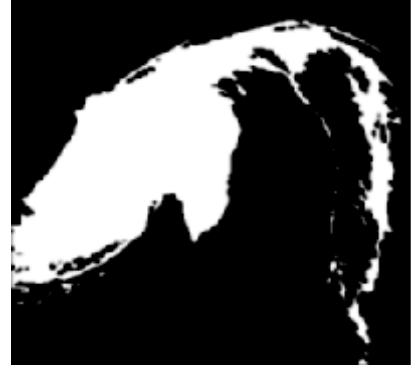

(e)
Column-2

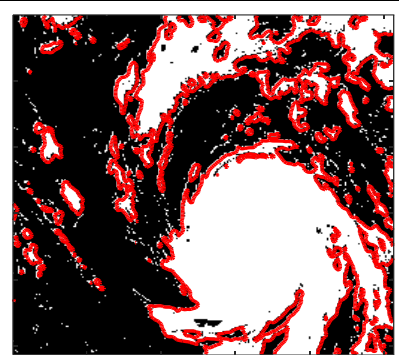

(b)

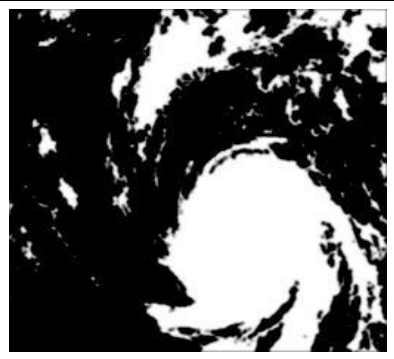

(f)
Column-3

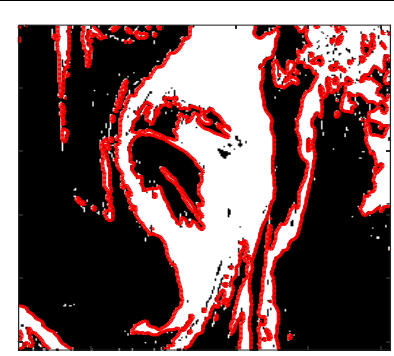

(c)

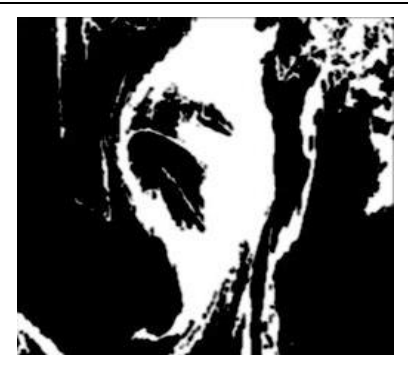

(g)
Column-4

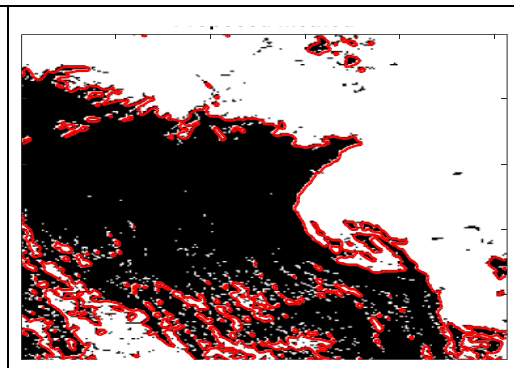

(d)

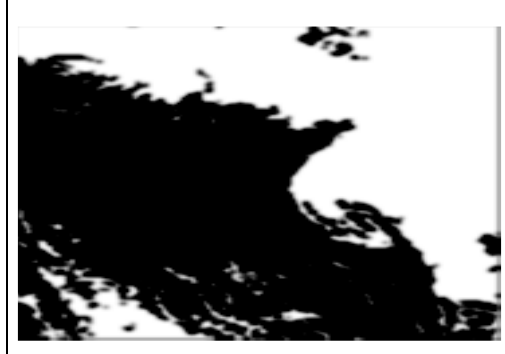

(h)

Figure 5 depicts the final segmentation regions are extracted by using proposed method, first row images shows the final contour evolution on pre-processed images and last row

shows the corresponding segmentation regions by final level set evolution are extracted objects such as oil slicker, oil spills, typhoon soulik and Gulf of Alaska.

Table 1: Performance of Conventional Methods on SAR images in terms of DS, JS, TPF, FNF and Elapsed time.

\begin{tabular}{|c|c|c|c|c|c|c|c|c|c|c|c|}
\hline S.No & Images & Method & $\begin{array}{c}\text { Area } \\
\text { covere } \\
\mathbf{d} \\
\left(\mathrm{mm}^{2}\right)\end{array}$ & $\begin{array}{c}\text { Actual } \\
\text { Area } \\
\left(\mathbf{m m}^{2}\right)\end{array}$ & $\begin{array}{c}\text { Area } \\
\text { error } \\
\left(\mathbf{m m}^{2}\right)\end{array}$ & DS & JS & TPF & FNF & $\begin{array}{c}\text { SA } \\
(\%)\end{array}$ & $\begin{array}{l}\text { Elapsed } \\
\text { Time(s) }\end{array}$ \\
\hline \multirow{4}{*}{1} & \multirow{4}{*}{$\begin{array}{l}\text { Oil } \\
\text { slicker } \\
\text { creeps } \\
\text { image }\end{array}$} & IVC 2010 & 44032 & 55696 & 11664 & 0.88 & 0.79 & 0.791 & 0.209 & 88 & 82.4546 \\
\hline & & Chan-Vese & 10926 & 55696 & 44770 & 0.21 & 0.19 & 0.196 & 0.080 & 21 & 50.9249 \\
\hline & & $\begin{array}{l}\text { ACM with } \\
\text { SBGFRLS }\end{array}$ & 22148 & 55696 & 33548 & 0.44 & 0.39 & 0.398 & 0.602 & 44 & 90.2614 \\
\hline & & ORACM & 19761 & 55696 & 35935 & 0.39 & 0.35 & 0.355 & 0.645 & 39 & 1.8835 \\
\hline \multirow{4}{*}{2} & \multirow{4}{*}{$\begin{array}{c}\text { Typhoon } \\
\text { soulik } \\
\text { image }\end{array}$} & IVC 2010 & 37853 & 55696 & 17843 & 0.75 & 0.67 & 0.679 & 0.320 & 75 & 19.3317 \\
\hline & & Chan-Vese & 10 & 55696 & 55686 & $\begin{array}{c}0.00 \\
02\end{array}$ & $\begin{array}{c}0.00 \\
01\end{array}$ & $\begin{array}{c}0.000 \\
1\end{array}$ & 0.999 & $\begin{array}{c}0.03 \\
5\end{array}$ & 74.8366 \\
\hline & & $\begin{array}{l}\text { ACM with } \\
\text { SBGFRLS }\end{array}$ & 29468 & 55696 & 26228 & 0.59 & 0.52 & 0.529 & 0.470 & 59 & 94.9321 \\
\hline & & ORACM & 26863 & 55696 & 28833 & 0.53 & 0.48 & 0.482 & 0.517 & 53 & 2.3432 \\
\hline \multirow{4}{*}{3} & \multirow{4}{*}{$\begin{array}{c}\text { Oil slick } \\
\text { image }\end{array}$} & IVC 2010 & 35304 & 55696 & 20392 & 0.70 & 0.63 & 0.633 & 0.366 & 70 & 21.605709 \\
\hline & & Chan-Vese & 25 & 55696 & 55671 & $\begin{array}{c}0.00 \\
08\end{array}$ & $\begin{array}{c}0.00 \\
04\end{array}$ & $\begin{array}{c}0.000 \\
4 \\
\end{array}$ & 0.999 & 0.08 & 42.7014 \\
\hline & & $\begin{array}{l}\text { ACM with } \\
\text { SBGFRLS }\end{array}$ & 15465 & 55696 & 40231 & 0.31 & 0.27 & 0.277 & 0.722 & 31 & 157.8172 \\
\hline & & ORACM & 23301 & 55696 & 32395 & 0.46 & 0.41 & 0.418 & 0.581 & 46 & 1.4528 \\
\hline \multirow{4}{*}{4} & \multirow{4}{*}{$\begin{array}{l}\text { Gulf of } \\
\text { Alaska }\end{array}$} & IVC 2010 & 16709 & 55696 & 38987 & 0.46 & 0.30 & 0.301 & 0.69 & 46 & 6.81147 \\
\hline & & Chan-Vese & 2 & 55696 & 55694 & 7.18 & 3.59 & 3.590 & 0.99 & 718 & 192.3958 \\
\hline & & $\begin{array}{l}\text { ACM with } \\
\text { SBGFRLS }\end{array}$ & 26813 & 55696 & 28883 & 0.65 & 0.48 & 0.481 & 0.51 & 65 & 32.9007 \\
\hline & & ORACM & 26496 & 55696 & 29200 & 0.64 & 0.47 & 0.471 & 0.52 & 64 & 3.0518 \\
\hline
\end{tabular}

Published By:

2046 Blue Eyes Intelligence Engineering \& Sciences Publication

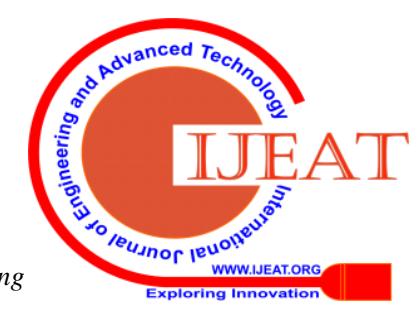


Table 2: Performance of proposed method on SAR images in terms of Area Covered by final contour, Area error and final cluster centers respectively.

\begin{tabular}{|c|c|c|c|c|c|c|}
\hline \multirow{2}{*}{ S.No } & \multirow{2}{*}{ Images } & \multicolumn{2}{|c|}{ Final cluster centers } & \multirow{2}{*}{ Area covered } & \multirow{2}{*}{ Actual Area } & \multirow{2}{*}{ Area error } \\
\hline & & Cc1 & Cc2 & & & \\
\hline 1 & $\begin{array}{c}\text { Oil slicker creeps } \\
\text { image }\end{array}$ & 102.1113 & 167.2374 & $45850 \mathrm{~mm}^{2}$ & $55696 \mathrm{~mm}^{2}$ & $9846 \mathrm{~mm}^{2}$ \\
\hline 2 & $\begin{array}{c}\text { Typhoon soulik } \\
\text { image }\end{array}$ & 53.2994 & 190.2392 & $39,514 \mathrm{~mm}^{2}$ & $55696 \mathrm{~mm}^{2}$ & $16,182 \mathrm{~mm}^{2}$ \\
\hline 3 & Oil slick image & 138.6437 & 185.7085 & $42649 \mathrm{~mm}^{2}$ & $55696 \mathrm{~mm}^{2}$ & $13,047 \mathrm{~mm}^{2}$ \\
\hline 4 & Gulf of Alaska & 58.8028 & 217.3925 & $32359 \mathrm{~mm}^{2}$ & $55696 \mathrm{~mm}^{2}$ & $23227 \mathrm{~mm}^{2}$ \\
\hline
\end{tabular}

Table i3: iPerformance iof iproposed imethod ion iSAR iimages iin iterms iof iDS, iJS, iTNF, iFNF iand iElapsed itime.

\begin{tabular}{|c|c|c|c|c|c|c|c|}
\hline S.No & Images & $\begin{array}{c}\text { Similarity } \\
\text { (DS) }\end{array}$ & $\begin{array}{c}\text { Jaccard } \\
\text { Similarity } \\
\text { (JS) }\end{array}$ & TPF & FNF & $\begin{array}{c}\text { Segmentation } \\
\text { Accuracy } \\
\text { (\%) }\end{array}$ & $\begin{array}{c}\text { Elapsed Time } \\
\text { (s) }\end{array}$ \\
\hline $\mathbf{1}$ & $\begin{array}{c}\text { Oil slicker } \\
\text { creeps } \\
\text { image }\end{array}$ & 0.91 & 0.82 & 0.823 & 0.176 & 91 & 8.0777 \\
\hline $\mathbf{2}$ & $\begin{array}{c}\text { Typhoon } \\
\text { soulik } \\
\text { image }\end{array}$ & 0.79 & 0.70 & 0.709 & 0.290 & 79 & 10.2870 \\
\hline $\mathbf{3}$ & $\begin{array}{c}\text { Oil slick } \\
\text { image }\end{array}$ & 0.85 & 0.76 & 0.765 & 0.23 & 85 & 10.5511 \\
\hline 4 & $\begin{array}{c}\text { Gulf of } \\
\text { Alaska }\end{array}$ & 0.73 & 0.58 & 0.583 & 0.417 & 73 & 12.40474 \\
\hline
\end{tabular}

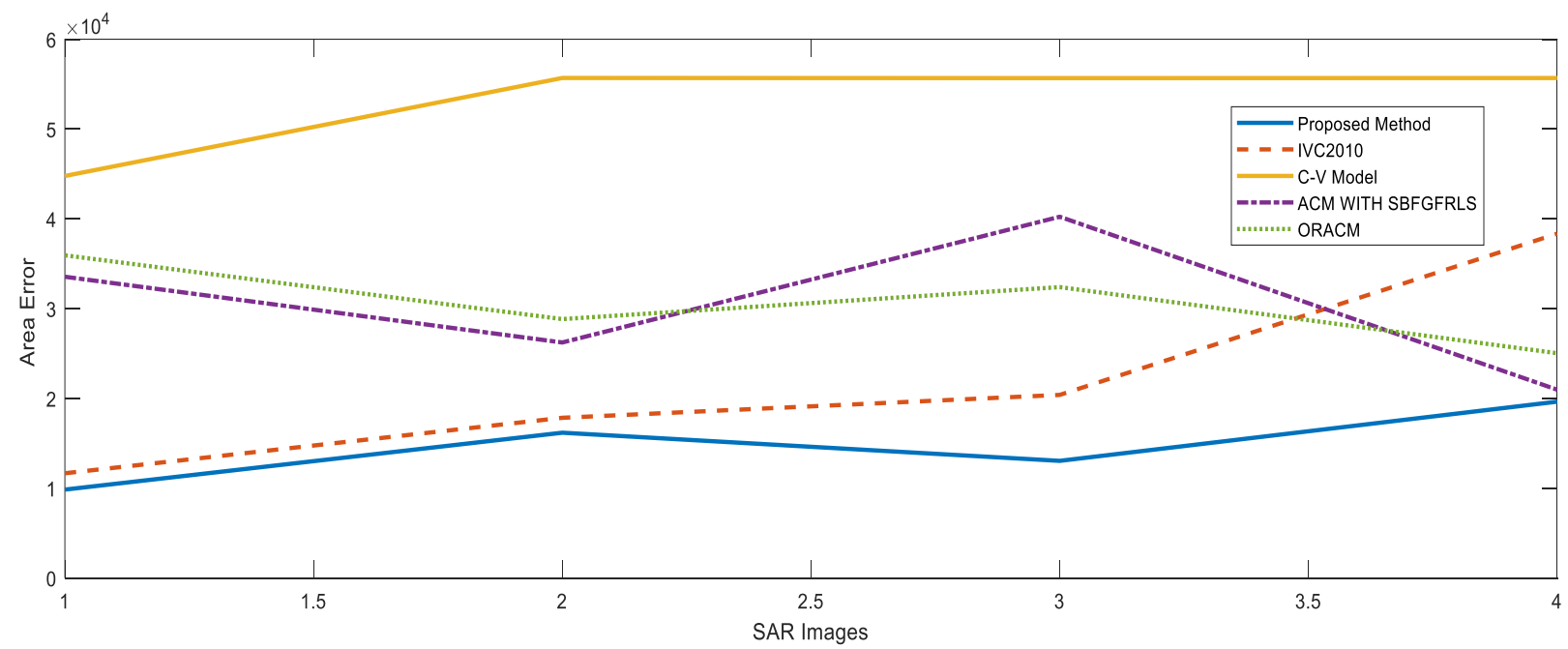

Figure 6. Shows the Performance graph of Existing and Proposed methods in terms of area error of four different Images 


\section{CONCLUSION}

Adaptive Fuzzy K-Means clustering using fast level set method is presented in this paper for efficient segmentation of remote sensing images such as oil slicker, oil spills images etc. This method is used to improve the clustering efficiency and information of mutually local as well as non-local are included into the AFKM objective utility which is modified by distance metric. By incorporating FCM and K-Means clustering in the pre-processing which is treated as Fuzzy-K-Means Clustering. Later stage, it is necessary to use post-processing via level set evolution for rejection of outliers, edge and boundary leakage problems in the pre-processing. The segmentation accuracy is measured based on similarity metrics such as Dice Similarity, Jaccard similarity, True Negative Fraction and False Negative Fraction. The proposed method was superior and more robustness over existing level set methods.

\section{REFERENCES}

1. E. Brown, T. Chan, and X. Bresson,. "Completely convex formulation of the Chan-Vese image segmentation model.," Int. J. Comput. Vis., volume. 98, no. 1, pp. 103-121, May 2012.

2. $\quad$ N. A. Mat-Isa, "Automated edge detection technique for Pap Smear images using moving k-means clustering and modified seed based region growing algorithm," International Journal of the Computer, the Internet and Management, volume. 13, pp. 45-59,. 2005.

3. $\mathrm{Xu}$, "An efficient local Chan-Vese model for image segmentation," Pattern Recognit., volume. 43, no. 3, pp. 603-618, Mar. 2010.

4. V.P Dinesh Kumar, and T. Thomas,. "Clustering of invariance improved Legendre moment descriptor for content based image retrieval," IEEE International Conference on Signal Processing, Communications and Networking, pp. 323-327, 2008.

5. N. A. Mat-Isa, M. Y. Mashor, and N. H. Othman, "Comparison of segmentation performance of clustering algorithms for Pap smear images". Proceedings of International Conference on Robotics, Vision, Information and Signal processing (ROVISP2003). pp. 118-125, 2003.

6. R. L. Cannon, J. V. Dave, and J. C. Bezdek, "Efficient implementation of the fuzzy c-means clustering algorithm" IEEE Trans. Pattern Analysis and Machine Intelligence, volume 8, pp 248-255, 1986.

7. T. Kanungo, D. Mount, N. Netanyahu, C. Piatko, R. Silverman, and A. Y. Wu "An efficient k-means clustering algorithm: analysis and implementation," IEEE Trans. on Pattern Analysis and Machine Intelligence, volume 24., No. 7, 2002.

8. M. Y. Mashor, "Hybrid training algorithm for RBF network," International Journal of The Computer, The Internet and Management, vol. 8, number. 2, pp. 50-65, 2000. C. Mao and S. Wan, "A water/land segmentation algorithm based on an improved Chan-Vese model with edge constraints of complex wavelet domain," Chin. J. Electron., volume 24, no. 2, pp. 361-365, Apr. 2015.

9. W. Cai, S. Chen, D. Zhang, Fast and robust fuzzy c-means clustering algorithms incorporating local information for image segmentation, Pattern Recogn. 40 (2007) 825-838.

10. S. Krinidis, V. Chatzis, A robust fuzzy local information c-means clustering algorithm, IEEE Trans. Image Process. 19 (2010) 1328-1337.

11. C. Li, C. Xu, C. Gui, and M. D. Fox, "Distance regularized level set evolution and its application to image segmentation," IEEE Trans. Image Process., volume 19, no. 12, pp. 3243-3254, Dec. 2010.

12. K. Zhang, L. Zhang, H. Song, and D. Zhang, "Reinitialization-free level set evolution via reaction diffusion," IEEE Trans. Image Process., volume. 22,no. 1, pp. 258-271, Jan. 2013.

13. L. Bertelli, S. Chandrasekaran, F. Gibou, and B. S. Manjunath, "On the length and area regularization for multiphase level set segmentation," Int. J. Comput. Vis., volume. 90, no. 3, pp. 267-282, Dec. 2010.

14. K. Karantzalos and N. Paragios, "Recognition-driven two-dimensional competing priors toward automatic and accurate building detection,” IEEE Trans. Geosci. Remote Sens., vol. 47, no. 1, pp. 133-144,Jan. 2009.
15. M. Kass, A. Witkin, and D. Terzopoulos, " Snakes, active contour model, " International Journal of Computer Vision, pp.321-331, 1988.

16. S. Ahmadi, M. J. V. Zoej, H. Ebadi, H. A. Moghaddam, and A. Mohammadzadeh, "Automatic urban building boundary extraction from high resolution aerial images using an innovative model of active contours," Int. J. Appl. Earth Observ. Geoinf., vol. 12, no. 3, pp. 150-157,Jun. 2010.

17. K. Kim and J. Shan, "Building roof modeling from airborne laser scanning data based on level set approach,” ISPRS J. Photogramm. Remote Sens.,vol. 66, no. 4, pp. 484-497, Jul. 2011.

18. M. Cote and P. Saeedi, "Automatic rooftop extraction in nadir aerial imagery of suburban regions using corners and variational level set evolution,"IEEE Trans. Geosci. Remote Sens., vol. 51, no. 1, pp. 313-328, Jan. 2013

19. S. N. Sulaiman and N. A. M. Isa: Adaptive Fuzzy-K-means Clustering Algorithm for Image Segmentation 2010 IEEE.

20. AbdenourMekhmoukh, karimmokrani."Improved Fuzzy C-Means based Particle Swarm Optimization (PSO) intialization and outlie rejection with level set methods for MR brain image segmentation" 2015 Elsevier Irekland Ltd.

21. C. Li, C. Y. Kao, J. C. Gore, and Z. Ding, "Minimization of region scalable fitting energy for image segmentation," IEEE Trans. Image Process., vol. 17, no. 10, pp. 1940-1949, Oct. 2008

22. S. Osher and R. Fedkiw, Level SetMethods and Dynamic Implicit Surface. New York, NY, USA: Springer-Verlag, 2002, pp. 123-124.

23. V. Caselles, R. Kimmel, and G. Sapiro, "Geodesic active contours," Int. J.Comput. Vis., vol. 22, no. 1, pp. 61-79, Feb./Mar. 1997.

24. C. Li, C. Xu, C. Gui, and M. D. Fox, "Distance regularized level set evolution and its application to image segmentation," IEEE Trans. Image Process., vol. 19, no. 12, pp. 3243-3254, Dec. 2010.

25. M. Maska, P. Matula, O. Danek, and M. Kozubek, "A fast level set-like algorithm for region-based active contours," in Proc. 6th Int Conf. Adv. Vis. Comput., 2010, Lect. Notes Comput Sci., volume. 6455, pp. 387-396.

26. Y. Yuan and C. He, "Adaptive active contours without edges," Math.Comput. Model., vol. 55, no. 5/6, pp. 1705-1721, Mar. 2012.

27. K. Zhang, L. Zhang, H. Song, and W. Zhou, "Active contours with selective local or global segmentation: A new formulation and level set method," Image Vis. Comput., vol. 28, no. 4, pp. 668-676, Apr. 2010.

28. S. K. Choy, M. L. Tang, and C. S. Tong, "'Image segmentation using fuzzy region competition and spatial/frequency information," IEEE Trans. Image Process., vol. 20, no. 6, pp. 1473_1484, Jun. 2011.

29. J. A. Sethian, Level Set Methods: Evolving Interfaces in Computational Geometry, Fluid Mechanics, Computer Vision, and Materials Science. Cambridge, U.K.: Cambridge Univ. Press, 1996.

30. B. N. Li, J. Qin, R. Wang, M. Wang, and X. Li, 'Selective level set segmentation using fuzzy region competition," IEEE Access, volume 4, pp. 4777_4788, 2016.

31. Lie, J., Lysaker, M., \& Tai,X. C. (2006).A binary Level Set model and some application to Munford-Shan image segmentation. IEEE Transaction on image processing 5,1171-1181.

32. Kama Ramudu and Tummala Ranga Babu "Layers and Dark sand dunes segmentation of MARS satellite Imagery Using Level Set Model" IETE Journal of Education. Volume 56,issue2,2010,(ISSN:-09747338),pp:59-67.

33. Ch.Kalyani, Ramudu Kama and GantaRaghotham Reddy, “A review on optimized K-means and FCM clustering techniques for biomedical image segmentation using level set formulation" in Biomedical Research (India)-An International Journal of Medical Sciences, volume.29,No.20, 2018, (ISSN: 0970-938X), pp: 3660-3668.

34. Ch.Kalyani, Ramudu Kama and GantaRaghotham Reddy, "Optimized Segmentation of Tissues and Tumours in Medical Images using AFMKM Clustering via Level Set Formulation" in International Journal of Applied Engineering Research (IJAER), volume .13,No.7, 2018, (ISSN:0973-4562), pp: 4989-4999.

35. Ramudu Kama, Kalyani Chinegaram, Ranga Babu Tummala, Raghotham Reddy Ganta."Segmentation of Soft Tissues and Tumors From Biomedical Images using Optimized K-Means Clustering via Level Set formulation", International Journal of Intelligent Systems And Applications, 2019,9,18-28 DOI: 10.5815/ijisa.2019.09.03 


\section{AUTHORS PROFILE}

Kalyani Chenigaram was born in Telangana, India in 1989. She received the B.Tech. and M.Tech. Degrees from JNTU, Hyderabad in 2011 and 2013, respectively. In 2019, she joined in the department of ECE as Assistant Professor to till date at Kamala Institute of Technology and Science, Huzurabad, Telangana state, India. She is having 5 years of teaching experience. She has published over 04 refered journal and conference papers in the areas of biomedical Image Processing as well as remote sensing Image processing. Her research interests include Image processing, Computer Vision and Signal Processing for communications.

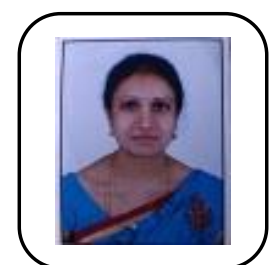

Lalitha Nagapuri was born in Telangana, India in 1985. She received the B.Tech. and M.Tech. Degrees from JNTU, Hyderabad in 2006 and 2010, respectively. In 2006 she joined in the department of ECE as Assistant Professor to till date at Kamala Institute of Technology and Science, Huzurabad, Telangana state, India. She is having 13 years of teaching experience. She has published over 4 refered journal and conference papers in the areas of biomedical Image Processing as well as wireless communication. Her research interests include Image processing, Computer Vision ,Signal Processing for communications and Wireless Communication.

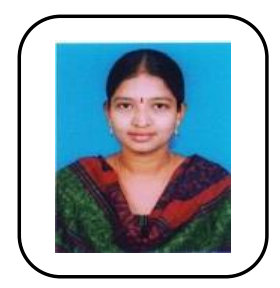

Chinta Nirosha was born in Telangana, India in 1986. She received the B.Tech. and M.Tech. Degrees from JNTU, Hyderabad in 2007 and JNTU, Kakinada in 2012, respectively. In 2013 she joined in the department of ECE as Assistant Professor to till date at DRK College of Engineering and technology,Hyderabad, Telangana state, India. She is having 7 years of teaching experience.She has published over 1 refered journal paper in the area of VLSI. Her research interests include VLSI and Signal Processing for communications.

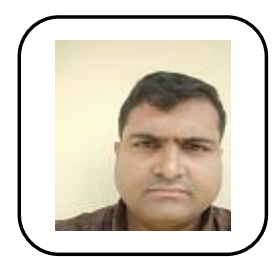

Srinivas Azmeera was born in Telangana, India in 1982. He received the B.Tech. and M.Tech. Degrees from JNTU, Hyderabad in 2005 and Kakatiya University, Warangal in 2007, respectively. In 2006, he joined in the department of ECE as Assistant Professor to till date at Kakatiya Institute of Technology and Science, Warangal, Telangana state, India. He is having 13 years of teaching experience. He has published over 14 refered journal and conference papers in the areas of biomedical Image Processing as well as remote sensing Image processing. His research interests include Image processing, Computer Vision and Signal Processing for communications. 